\title{
Strategy Study of Coordinated Development between Mass Sports and Competitive Sports
}

\author{
Jin Mei Shao ${ }^{1, a^{*}}$ and Lei $\mathrm{Li}^{2, \mathrm{~b}}$ \\ ${ }^{1}$ Hebei United University, China \\ ${ }^{2}$ Tangshan Vocational \& Technical College, China \\ aemail: shaojinmei356@126.com, bemai:644513492@qq.com
}

Keywords: Mass sports; Competitive sports; Coordinated development; Public health; Physical exercise.

\begin{abstract}
The mass sports and competitive sports are very important parts in sports cause in China. Coordinated development of mass sports and competitive sports acts as precondition for sports rapid development in new era in China. In the paper, strategy of coordinated development between mass sports and competitive sports is studied for analyzed the relationship between mass sports and competitive sports as well as problems during coordinated development between the two. Strategy of coordinated development between mass sports and competitive sports is proposed finally, thereby promoting coordinated development between mass sports and competitive sports.
\end{abstract}

\section{Introduction}

Athletes can achieve excellent results and rank top positions in competitive sports all over the world in various major sports events. It is obvious that China competitive sports enjoy higher development level, however development of mass sports cause is relatively slow relatively, 'shortcomings' of mass sports have become obstacles for China to develop into sports power. Therefore, development of mass sports cause should be strengthened, the action between mass sports and competitive sports is focused, thereby promoting coordinated development between mass sport and competitive sports in China.

\section{Relation between Mass Sports and Competitive Sports}

Mass sports are basis for sustainable development of competitive sports. Mass sports are the basis for sustainable development of competitive sports, achievements of competitive sports are inevitable results of mass sports which are developed to certain level. Sound development of mass sports can promote increase of sports population in China. More reserve talents with high level can be selected from huge sports population, which are added into competitive sports team, thereby improving competitive level in China and developing competitive sports. Therefore, mass sports are the basis of competitive sports, which act as basis for high level competitive sports. Competitive sports talents show high skill for attracting excellent sports talents in mass sports. It can drive mass sports team to actively participate in exercise, thereby promoting improvement of mass sports level. Mass sports team is enhanced, competitive sports level can be well improved, and competitive sports level is improved, therefore excellent achievements can be created in China. All people can be encouraged to participate in sports. Therefore, harmonious development between mass sports and competitive sports lays a solid development for sustainable development of sports cause in China.

Competitive sports have functions of leading and demonstrating mass sports. Competitive sports have characteristics of competitiveness, craft, entertainment and internationality. Intense competition makes competitive sports more attractive. Uncertainty of competition results attracts people's attention and curiosity, and people can devote own strong emotion. When athletes achieve success in the international arena, national spirit and pride of people can be inspired and cheered up, thereby people can produce strong desire to exercise. High skills of competitive sports are more 
ornamental and artistic. When people appreciate skills with high difficulty, idol is regarded as an example, and people can consciously participate in national fitness. Competitive sports have high entertainment, the masses can relieve and relax themselves through appreciating competitive sports activity after busy work. Athletes can exchange, mutually comprehend and enhance friendship through competition due to its wide internationality. People can participate in mass sports activities through competitive sports. Wide exchange space can be provided for people, people's enthusiasm of participating in activities can be improved, thereby promoting flourishing development of mass sports cause.

\section{Problem in Coordinated Development between Mass Sports and Competitive Sports}

Coordinated development level between mass sports and competitive sports is far lower than theoretical study. Coordinated development between mass sports and competitive sports has become a major trend in current sports development; good social and psychological environment is a prerequisite to achieve coordinated development, school sports act as important basis for coordinating development between competitive sports and mass sports. The club is the organization form for coordinating integration between competitive sports and mass sports. Emphasis on community sports is powerful guarantee for coordinated development between mass sports and competitive sports. Mass sports is the basis for competitive sports at high level, and competitive sports also can greatly promote mass sports. It is obvious that related exploration and research have accumulated a wealth of theoretical basis for development of competitive sports and mass sports. However, whether these theories meet practical requirements of sports development in China still should be tested by practice. Development level between mass sports and competitive sports in China is introspected, which can not meet development needs of socialist modernization construction cause in China. The coordinated development still has some unsolved problems as a process of development, and it should be further developed as an ideal target.

Competitive sports form contrast with mass sports coordinated development with priority. Limited physical resources are highly concentrated for realizing the goal of competitive sports under the condition of nationwide sports, competitive sports are undoubtedly placed in the position of priority development. It is required that competitive sports and mass sports should be controlled synchronously under the guidance of coordinated development strategic thinking. People are not willing to give up national sports system due to vested interests and habit force which are formed for many years during key transfer period of sports work. National fitness is located in an awkward situation for term in concrete work. Therefore, mass sports form great contrast with competitive sports development level in China. Such statement does not refuse achievements in the aspect of China mass sports for recent 60 years. Competitive sports can reach world leading level in short term relatively, and mass sports still should be greatly improved. As some scholars believe that: China sports achieve unprecedented achievements in the past under the ideological guidance of laterally focusing on improvement, therefore China mass sports lag behind competitive sports.

Mass sports funding, venue facilities and other resources are scarce in China. Development of mass sports is based on the level of social development, which relies on manpower, financial strength, information and other resources provided by the society. Therefore, speed and scale of mass sports development depend on national economy production level. China has vast area, north-south regional differences are great, development of east and west regions is uneven, which is affected by level of national economic development. Development of mass sports in China suffers from regional differences, which is generally manifested as sound development of mass sports in downtown area, which is centered on metropolis. Vast rural area with underdeveloped economy is at a low level. Although great progress for China economy provides powerful comprehensive national support for mass sports in recent years, it also provides excellent economic background for sports participation among wider urban and rural residents. Growing sports demand is also proposed, therefore overall level of mass sports in China has been rapidly improved. However, we can not deny that geographical 
gap of mass sports does not appear because of objective existence of inter-regional differences in economic and social development level, on contrary, the gap is further enlarged, which is limited by lifestyle, sports concept, sports venue facilities and other conditions. Mass sports in vast rural areas are still in lower level in terms of participation and achieved degree.

\section{Strategy of Coordinated Development between Mass Sports and Competitive Sports}

Determination of sports concept of all citizen participation, and reinforcement of sports modernization reform. Mass sports are fundamental guarantee for sports cause development in China. Sports cause can not be developed without participation of mass sports. It is critical to guide the mass to actively participate in sports activity. Teenagers can be cultivated for enjoying sports and sports process in school from childhood. Regional competition can be organized regularly according to plan, thereby accelerating construction of stadiums. Development of mass sports can be fully driven by university resources, thereby providing guarantee for diversifying competitive sports. Community should timely care the elderly in own jurisdiction, and actively promote mass participation in physical exercise. Company and unit should respond to national call positively, young employees should be organized for participating in various sports activities benefiting mind and body, such as hiking, biking, etc. Therefore all people can actually participate in sports.

Development relation between mass sports and competitive sports is correctly handled. We should implement extensive sports activities according to national outline and document spirit about sports cause development. It is powerful guarantee for promoting competitive sports to develop continuously to scientific, healthy and sustainable direction. Coordinated development between mass sports and competitive sports is related to people's physical health, life quality and development of the sports industry, and it is an important part for building harmonious society. We should change the concept, and balance status of mass sports and competitive sports, balance between the two statuses determines scientific development degree of sports cause. National fitness is substantially improved due to flourishing development of mass sports, and life happiness index is also rising, which can really provide more talents with higher quality for competitive sports. Therefore, focus on deep link and harmonious between mass sports and competitive sports has become important foundation for the core growth of sports cause.

Lever regulation function of sports competition on coordination development is emphasized. Many sport competitions in China adopt 'national fitness and public participation' as slogan. Mass sports content only appears at the performance of opening ceremony. Professional athletes play the game on the playing area, thereby being lack of mass participation in competition. It is really hard to understand the promotion function of the mode of implementing 'National Fitness Program Outline' on mass sports. The government determined annual August 8 as National Fitness Day since 2009 aiming at calling people to practice national fitness. Mass sports cause in China is driven to higher level. The function that sports competition acts as participation booster in sports activities should be fully exerted. Management on sports competition should be strengthened. Though we call all people to participate in sports, some public fitness events should be integrated into competition. Diverse and multi-level competition systems are adopted so that more people can participate in the sports, review of competition participation eligibility should be reinforced, thereby preventing unfair impostor phenomena, and stimulating enthusiasm and initiative of national fitness.

Creation of Sound Atmosphere of National Fitness. China sports cause can fundamentally solve problems only by enlarging reform strength and developing appropriate measures. Funding investment should be increased in competitive sports and mass sports, sports special fund system is established and perfected, such as setup of competition sports special fund and national fitness charity fund. National government invests and implements sports cause funding. National financial fund allocation is mainly used for national sports organization institution activity, competitive sports key events and construction of national training base. Local fund allocation is applied for mass sports organizations to develop sports activities, construct sports venue facilities, and cultivate reserve 
talents in sports. Planning and construction of public sports infrastructure are increased, especially construction of small sports venues and fitness venues. Individual investment is encouraged for constructing sports events, and preferential policies are provided. Sports venues are open to the public, charges must be acceptable for masses. We should focus on expansion and construction of mass sports teams, and develop social sports instructors in large scale, therefore allocation proportion of the mass and sports instructors is rational. New policies and regulations are implemented, management is sufficient, propaganda strength of national fitness activities is reinforced, thereby forming fitness public opinion guidance, creating fitness public opinion atmosphere, enhancing people's awareness of fitness, improving enthusiasm of public participation in fitness, shortening differences in urban and rural areas, regions and ages. Chinese population actively participating in sports exercise can be more than world sports powers.

\section{Summary}

Physical exercise is beneficial for enhancing national constitution and physique in China, and achieving higher level of national constitution and competitive application in China. Coordinated development between mass sports and competitive sports is very important. Relationship between mass sports and competitive sports is analyzed for discussing problems in coordinated development, thereby proposing corresponding solutions. In the paper, China should determine sports concept of national participation, reform of sports modernization is reinforced; development relationship between mass sports and competitive sports should be properly handled; lever regulation function of sports competition on coordination development is focused, and sound national fitness atmosphere is created. Coordinated development between mass sports and competitive sports is promoted, which is beneficial for forming homonymous crossed healthy development between mass sports and competitive sports in China, and sports cause in China is flourishingly developed.

\section{References}

[1] YE Baohua, ZHOU Guokui. Reflections on Coordinated Development of Mass Sports and Competitive Sports after Beijing Olympic Games, J. Sports Science Research. 2010(02):39-41.

[2] LI Can. Developemnt of Amateur and Competitive Sports on the Sprots Course in China The Research into the Far-reaching Influence of Coordinated, J. Journal of Nanjing Institute of Physical Education(Natural Science). 2011(01):6-10.

[3] LI Jing. On Harmonious Development of Athletic Sports and Mass Sports from a Sociological Perspective, J. Sports Science Research. 2011(03):49-51.

[4] FU Zhengming. Discussion on the Formation Process of Mass Sports with Chinese Characteristics , J. Journal of Southwest China Normal University(Natural Science Edition).2011,36(3):101-104.

[5] ZHAO Zheng. The Research of Competitive Sports and Mass Physical Education Coordinated Development, J. Journal of Anyang Normal University. 2011(05):120-123.

[6] LIU Meiying, IAN Yupu, HOU Liping. Development countermeasures of Chinese sport for all in view of being strong in sports, J. Journal of Wuhan Institute of Physical Education. 2009,3(7):9-13.

[7] CHENG Wenguang. Thought Resources in the Changes of Mass Sport and Athletic Sport, J. Journal of Shenyang Sport University.2006,25(6):1-3.

[8] PEI Lixin, HUANG Wei, TONG Qiang. Research on Relationships between Sports and Mass Sports in China, J. Journal of Sports and Science.2008,29(1):67-70. 
[9] LIANG Riwei, YANG Guocheng. Research into the tendency of harmonious development of mass sport and competitive sports, J. Journal of Xinyu University. 2014,19(4):72-75.

[10]DONG Hongwei. Equilibrium and Disequilibrium: Theoretical Mode and Actual Choice Between Competitive Sports and Mass Sport, J. Journal of Shenyang Sport University.2011,30(2):8-11.

[11]LIU Xinhua. Study on Strategy of Establishing Powerful Mass Sports in China, J. China Sport Science and Technology.2010,46(1):19-31.

[12] GU Dehong, WU Yigang. Analysis on Basic Theory of Competitive Sports Development Way, J. Journal of Beijing Sport University.v2014,37(10):7-12. 